\title{
Perioperatif Anestesia pada Pasien Seksio Sesarea dengan Skizofrenia
}

\author{
Ayu Rosema Sari' ${ }^{1}$, Dewi Yulianti Bisri², Yusmein Uyun ${ }^{3}$ \\ ${ }^{1}$ Peserta didik Subspesialis Minat Anestesi Obstetri Anestesiologi \& Terapi Intensif FKKMK Universitas Gadjah \\ Mada/RSUP Dr Sardjito Yogyakarta, ${ }^{2}$ Departemen Anestesiologi \& Terapi Intensif Fakultas Kedokteran Universitas \\ Padjadjaran/RSUP Dr. Hasan Sadikin Bandung, ${ }^{3}$ Departemen Anestesiologi \& Terapi Intensif FKKMK Universitas \\ Gadjah Mada Yogyakarta/RSUP Dr. Sardjito Yogyakarta
}

\begin{abstract}
Abstrak
Pasien hamil dengan gangguan kejiwaan menjadi kasus yang menantang bagi ahli anestesi obstetri. Seorang ahli anestesi obstetri harus menyadari aspek hukum, etika, dan medis dari kondisi tersebut dan menyelesaikan setiap masalah secara individual. Penilaian pra operasi dan persiapan harus disesuaikan dengan jenis gangguan pasien. Pilihan teknik anestesi tergantung pada status mental pasien, dan perawatan pasca operasi (pemberian obat anti nyeri dan kelanjutan terapi medis penyakit kejiwaan) harus dikelola dengan baik. Seorang wanita 37 tahun, G2P1A0 hamil 40 minggu dengan skizofrenia dilakukan tindakan seksio sesarea, pasien rutin mengkonsumsi obat antipsikotik. Pasien sempat mengalami penundaan operasi karena tidak kooperatif sehingga dikonsulkan ulang ke psikiater. Teknik pembiusan dengan spinal anestesi menggunakan bupivacaine heavy 10mg. Selama operasi berlangsung hemodinamik stabil, tekanan darah sistolik 100-130 mmHg, diastolik 60-90 mmHg, nadi 80-95x/menit, laju nafas 16-20x/menit dengan saturasi oksigen 100\%. Bayi lahir 2 menit setelah insisi dengan Apgar score 8/10. Penanganan pasien skizofrenia yang akan dilakukan tindakan seksio sesarea membutuhkan pemahaman yang baik agar tidak terjadi morbiditas maupun mortalitas, mengingat gangguan kejiwaan adalah hal yang cukup lazim terjadi.
\end{abstract}

Kata kunci: perioperatif, seksio sesarea, skizofrenia

\section{Perioperative Anesthesia in Cesarean Section Patients with Schizophrenia}

\begin{abstract}
Pregnant patients with psychiatric disorders present as challenging cases for obstetric anesthetists. An obstetric anesthetist should be aware of legal, ethical, and medical aspects of the conditions and solve each problem on a individual basis. Preoperative assessment and the preparation should be adjusted according to the type of patient's disorder. Choice of anesthetic technique should actively be dependent on the mental status of the patient, and postoperative care should be attentively managed regarding pain relief and continuation of medical therapy for the psychiatric disease. A 37-year-old woman, G2P1A0, 40 weeks pregnant with schizophrenia, was performed a cesarean section, patient taking antipsychotic drugs. Anesthetic technique with spinal anesthesia uses Bupivacaine heavy $10 \mathrm{mg}$. During the operation hemodynamically stable, systolic blood pressure $100-130 \mathrm{mmHg}$, diastolic 60 $90 \mathrm{mmHg}$, pulse $80-95 \mathrm{x} / \mathrm{min}$, breathing rate $16-20 \mathrm{x} / \mathrm{min}$ with $100 \%$ oxygen saturation. The baby is born 2 minutes after incision with an Apgar score 8/10. Management of schizophrenia patients who will undergo cesarean section requires a good understanding to prevent morbidity and mortality, considering psychiatric disorders are quite common.
\end{abstract}

Key words: perioperative, cesarean section, schizophrenia 


\section{Pendahuluan}

Gangguan kejiwaan adalah hal yang cukup lazim terjadi pada manusia, memberikan angka morbiditas yang cukup signifikan bagi populasi umum dan pada wanita dengan usia reproduktif. Kelainan yang bisa terjadi adalah gangguan $\mathrm{mood}$, kecemasan, psikotik, gangguan pola makan dan kepribadian. ${ }^{1}$ Diakui bahwa onset dan eksaserbasi gangguan kejiwaan yang terjadi selama periode kehamilan dan post partum adalah masalah yang cukup sering terjadi dan membutuhkan pendekatan multidisiplin agar dapat dilakukan diagnosis serta terapi tepat efektif. Terlepas angka prevalensinya yang cukup tinggi, sering kondisi ini tidak terdiagnosa, tidak diterapi atau bahkan salah diagnosa. Terapi farmakologi selama kehamilan beresiko terhadap janin akan tetapi jika ibu tidak mendapat terapi juga memberikan resiko kekambuhan. Secara rasional, skrining pasien lebih disarankan sebelum konsepsi untuk memberikan perencanaan yang tepat dan efektif. ${ }^{2}$

Sekitar $1 \%$ dari populasi dunia menderita skizofrenia. Skizofrenia adalah gangguan otak kronis dengan gejala delusi, halusinasi, gangguan berfikir, konsentrasi dan hilangnya motivasi. ${ }^{3}$ Pasien biasanya menunjukkan gejala awal saat masih berusia muda (20-30 tahun), namun penyakit ini bisa terjadi pada semua tingkatan usia dan mempengaruhi baik laki-laki maupun perempuan dengan tingkat resiko yang sama. Tingkat kekambuhannya sangat tinggi jika tidak dilakukan tindakan pengobatan dan perawatan yang tepat. ${ }^{2}$ Di masa lampau, wanita dengan skizofrenia dikatakan memiliki fertilitas yang lebih rendah dibandingkan wanita pada populasi umumnya. Akan tetapi, penelitian terbaru mengatakan bahwa saat ini kejadian skizofrenia pada wanita mendekati rata-rata populasi, sehingga penting adanya konseling efektif dan manajemen pada wanita dengan skizofrenia yang sedang maupun berencana hamil. Informasi tentang prevalensi dan faktor resiko gejala psikotik selama periode perinatal diharapkan dapat membantu ibu, keluarga dan penyedia layanan kesehatan untuk mengurangi resiko kekambuhan yang mungkin terjadi. ${ }^{4}$ Menghitung prevalensi wanita hamil dengan skizofrenia cukup sulit, karena sebagian besar studi berdasarkan sampel di rumah sakit saja. Salah satu penelitian yang dilakukan terhadap 45 wanita skizofrenia yang dirawat di unit ibu-bayi pasca melahirkan. ${ }^{5}$ Mayoritas dari mereka dilaporkan menderita gejala psikotik selama kehamilan $(71 \%-94 \%)$, disamping adanya fakta penggunaan obat psikotropika dalam kehamilan. ${ }^{5}$ Penelitian lain melaporkan $12 \%$ wanita yang rawat inap dengan psikosis pasca melahirkan terdiagnosa sebagai skizofrenia. ${ }^{6}$ Satu penelitian juga menyebutkan dari 82 wanita yang rawat inap di rumah sakit dengan gejala psikiatri pasca melahirkan, $18 \%$ di antaranya terdiagnosa skizofrenia. ${ }^{6}$

Evaluasi preoperatif pasien yang dicurigai atau sudah terdiagnosa gangguan kejiwaan merupakan hal yang cukup penting agar dapat dipahami jenis dan keparahan gangguan yang ada. Informasi tentang penggunaan terapi farmakologi pada pasien juga harus didapatkan agar dapat diketahui kemungkinan adanya interaksi dengan obat anestesi. $^{7}$

\section{Kasus}

\section{Anamnesa}

Pasien umur 37 tahun hamil $40 \mathrm{mg}$ dengan skizofrenia, sebelum hamil sudah menderita gangguan skizofrenia ( \pm 1 tahun) dan sudah berobat ke RSJD Soedjarwadi Klaten, pernah rawat inap 16 hari. Selama ini minum obat clozapine $25 \mathrm{mg}(1 / 4-1 / 2$ tab) setiap malam setelah makan malam dan risperidone $2 \times 1 / 2$ tab.

\section{Pemeriksaan Fisik}

Saat dilakukan pemeriksaan didapatkan pasien sadar, kadang muncul halusinasi dan autism. Hemodinamik pra operasi tekanan darah 118/72 $\mathrm{mmHg}$, nadi 98x/menit, laju nafas 20x/menit, suhu afebris dan skala nyeri VAS 2. Pemeriksaan penunjang $\mathrm{Hb} 12,6 \mathrm{~g} / \mathrm{dL}$; AL 9,103/uL; AT 196.103/uL; Hmt 38,5 vol\%; eritrosit 4,78.106/ $\mathrm{uL}$; ureum $16,6 \mathrm{mg} / \mathrm{dL}$; creatinine $0,4 \mathrm{mg} / \mathrm{dL}$; SGOT 17 U/L; SGPT 19 U/L; GDS 105 mg/dL; PT 12,6 det; APTT 25,2 det; HBsAg negatif; anti HIV non reaktif; EKG NSR 99x/menit. Dilakukan konsultasi dengan TS SpKJ saran: obat clozapine stop, risperidone $2 \mathrm{mg}$ diberikan 1 tab 12 jam 
sebelum operasi dan diberikan lagi post operasi. Pasien tidak boleh menyusui selama minum obat. Saat akan dibawa ke kamar operasi pada pukul 10.00, pasien mengamuk dan tidak kooperatif sehingga operasi ditunda, konsul SpKJ mendapat terapi clozapine dan direncanakan operasi jika pasien sudah kooperatif.

\section{Pengelolaan Anestesi}

Jam 23.40-00.20 dilakukan tindakan SC dengan teknik SAB, SP, L3-4, Ø25G, LCS + jernih, obat bupivacain heavy $10 \mathrm{mg}$. Selama pembiusan dan operasi pasien kooperatif sehingga tidak dilakukan sedasi. Selama operasi tekanan darah sistolik 100 $130 \mathrm{mmHg}$, diastolik 60-90 mmHg, nadi 80-95 x/ menit, laju nafas 16-20 x/menit dan $\mathrm{SpO}_{2} 100 \%$. Bayi lahir jam 23.50 (2 menit setelah insisi) dengan jenis kelamin laki-laki dan AS 8/10. Diberikan obat secara intravena: Granisetron 1mg, parasetamol 1gr, oxytocin $10 \mathrm{IU}$ (drip dalam RL) dan methylergometrin 0,2mg. Durante operasi masuk cairan RL1500mLdan urine output $400 \mathrm{~mL}$.

\section{Pengelolaan Pascabedah}

Di ruang pemulihan tekanan darah sistolik 100 $135 \mathrm{mmHg}$, diastolik $65-70 \mathrm{mmHg}$, nadi $70-85$ $\mathrm{x} /$ menit, laju nafas 16-20 x/menit dan $\mathrm{SpO}_{2}$ $100 \%$. Pasien mendapatkan terapi post operasi IVFD RL 15 tpm, fentanyl 100mcg+ketorolak $60 \mathrm{mg}$ dalam $500 \mathrm{~mL}$, asering $15 \mathrm{tpm}$, granisetron $1 \mathrm{mg}$ IV/24 jam. Setelah dilakukan observasi 30 menit di ruang pemulihan, pasien dikembalikan ke bangsal rawat inap dengan Bromage Score 3.

\section{Pembahasan}

Evaluasi pra operasi pada pasien yang dicurigai atau sudah terdiagnosa skizofrenia melibatkan psikolog atau psikiater. Penggunaan obat juga ditanyakan agar diketahui ada tidaknya intoksikasi untuk memaksimalkan penatalaksanaan nyeri pada persalinan dan anestesi. ${ }^{8}$ Pasien pada kasus ini telah dilakukan konsultasi pra operasi kepada psikiater setelah dari anamnesa didapatkan riwayat menderita skizofrenia serta rutin mengkonsumsi clozapine dan risperidone. Perlu diperhatikan bahwa pasien dengan gangguan psikiatri yang ingin hamil sering berhenti mengkonsumsi obat terutama anti depresan, karena beresiko negatif terhadap janin dan kehamilan misalnya abortus spontan, lahir mati, hipoglikemia, penyakit kuning, diabetes gestasional, kejang, berat lahir rendah dan juga kelainan katup jantung. Pasien seperti ini datang ke rumah sakit atau kamar operasi dengan kemungkinan terjadi leukopenia, somnolen, pusing (vertigo) maupun kondisi depresi, hipomania, mania dan episode psikosis. ${ }^{9}$

Pemeriksaan laboratorium pra operasi pada pasien hamil dengan skizofrenia yang akan dilakukan tindakan seksio selain pemeriksaan standart juga memerlukan pemeriksaan yang berhubungan dengan efek samping atau kontraindikasi obat psikosis yang digunakan. Penggunaan clozapine dapat menyebabkan agranulositosis sehingga diperlukan pemeriksaan jumlah sel darah putih (AL) dan jumlah absolut neutrofil, pengobatan akan dilanjutkan jika $\mathrm{AL} \geq 3500$ / $\mathrm{mm} 3$ dan neutrofil $\geq 2000 / \mathrm{mm} 3$. Diperlukan juga pemeriksaan trombosit (AT), jika turun di bawah 50000/mm3 maka clozapine harus dihentikan. Kemudian juga pemeriksaan fungsi ginjal dan hepar, karena pemberian obat ini kontraindikasi pada pasien dengan gangguan ginjal berat dan penyakit hati. ${ }^{10}$ Risperidone dilaporkan dapat menyebabkan kenaikan kadar CPK (Creatine Phosphokinase) yang jika itu terjadi maka obat harus segera dihentikan. Kadang juga terjadi peningkatan enzim hati, intoksikasi air dengan hyponatremia, sedikit penurunan neutrofil dan trombosit. ${ }^{11}$ Pemeriksaan fungsi hati, elektrolit dan trombosit perlu dilakukan pada pasien yang mengkonsumsi risperidone. Pada pasien ini hanya pemeriksaan jumlah absolut neutrofil yang tidak dilakukan, sedangkan pemeriksaan lain dilakukan dan hasilnya dalam batas normal.

Tidak kalah pentingnya dalam evaluasi pra operasi adalah kemampuan pasien dalam memahami tindakan anestesi yang akan diterima. ${ }^{12}$ Hal ini berpengaruh terhadap siapa yang akan menandatangani lembar penjelasan dan persetujuan anestesi jika pasien dianggap tidak mampu secara hukum. Untuk pasien ini saat masuk kondisi sadar dan kooperatif sehingga penandatanganan lembar tersebut dilakukan oleh pasien sendiri dan suami sebagai saksi keluarga. Pemilihan teknik anestesi tergantung pada 
kondisi pasien. Anestesi umum dipilih jika ada gangguan sistem neuromuskular. Gerakan tidak disengaja dan tics dapat mengganggu pelaksanaan teknik anestesi regional dan bahkan proses pembedahan. ${ }^{13}$ Kondisi kejiwaan yang ekstrim, misal delirium, katatonik, tidak sadar, agitasi hebat dan pasien yang takut jarum merupakan kriteria yang memerlukan tindakan dengan anestesi umum. Pasien dengan kondisi kejiwaan yang stabil seperti pada kasus ini disarankan untuk dilakukan anestesi regional baik spinal, epidural maupun kombinasi spinal epidural. ${ }^{14}$ Perlu diperhatikan bahwa mekanisme kerja anti psikotik pada reseptor-1 adrenergik menyebabkan penurunan resistensi pembuluh darah perifer sehingga mengakibatkan hipotensi ortostatik. Pasien yang dilakukan tindakan pembiusan dapat mengalami hipotensi, kehilangan panas dan faktor komplikasi yang mungkin terjadi adalah kompensasi kehilangan darah yang tidak adekuat. Efek lain yang bisa terjadi adalah perubahan pada EKG, meliputi kenaikan gelombang PR, QRS dan QT. Jika ada blok jantung juga bisa memburuk. ${ }^{15}$ Pemeriksaan pre operatif pada pasien ini didapatkan hasil EKG NSR HR 99 x/menit meskipun mengkonsumsi obat antipsikotik selama kehamilan. Teknik pembiusan dengan spinal anestesi bupivacain heavy 10mg dengan ketinggian L3-4, durante operasi monitoring hemodinamik stabil dengan tekanan darah sistolik terendah $100 \mathrm{mmHg}$ dan diastolik terendah $60 \mathrm{mmHg}$.

Efek samping yang bersifat mengancam jiwa pada penggunaan obat antipsikotik adalah sindroma neuroleptik maligna, dengan gejala peningkatan suhu tubuh secara tiba-tiba, kekakuan otot, demam, tekanan darah tidak stabil, diaforesis dan perubahan kesadaran (agitasi, delirium sampai koma). Gejala ini akan muncul dalam hitungan jam sampai minggu. Sindroma neuroleptik maligna ini diakibatkan oleh penurunan aktifitas dopamin secara tiba-tiba sehingga terjadi termoregulasi yang tidak normal dan rigiditas otot. Prevalensi kejadian sekitar $0,02 \%-2,4 \%$. Pemakaian droperidol, suksinilkolin, haloperidol dan metoklopramid pada pasien harus hati-hati agar tidak menyebabkan sindroma tersebut. ${ }^{16}$ Pasien dalam kasus ini tidak menggunakan obat- obatan tersebut sehingga kemungkinan terjadinya sindroma neuroleptik maligna lebih kecil.

Tidak jarang pasien skizofrenia disertai dengan gangguan mood, kondisi ini dikenal dengan istilah gangguan skizoafektif, sehingga diperlukan tambahan obat antidepresan. ${ }^{17}$ Salah satu jenis antidepresan yang berpengaruh dalam anestesi adalah obat antidepresan golongan tricyclic antidepressants (TCAs) yang memiliki reseptor $\alpha 1$ antagonis, antikolinergik adan antihistamin. Efek yang ditimbulkan akibat penggunaan obat golongan ini bervariasi, misal hipotensi ortostatik, takikardia, bibir kering, konstipasi, dan sedasi. Hipotensi intraoperasi pada pasien yang mendapatkan terapi TCAs disebabkan vasodilatasi perifer (blokade $\alpha$ adrenergik) atau penurunan kontraktilitas miokard. Untuk hipotensi terkait TCAs, ada ketidaksepakatan tentang cara terbaik untuk mengobatinya. Durasi pengobatan TCAs juga harus dipertimbangkan. ${ }^{18}$ Dalam pengobatan TCAs jangka pendek, pasien dapat merespons simpatomimetik yang bekerja tidak langsung seperti efedrin karena peningkatan ketersediaan norepinefrin presinaptik. Sebaliknya, dalam pengobatan jangka panjang, TCAs menyebabkan desensitisasi adrenergik, dan lebih dari itu, deplesi katekolamin dapat memperburuk respon terhadap simpatomimetik. ${ }^{19}$ Simpatomimetik yang kurang kuat mungkin tidak efektif untuk hipotensi pada pasien pengobatan TCAs jangka panjang karena reseptor adrenergik mengalami desensitisasi dan penyimpanan katekolamin habis. ${ }^{20}$ Menipisnya simpanan norepinefrin akibat TCAs menyebabkan blokade reseptor adrenergik perifer dan memblokir pengambilan kembali norepinefrin dan dopamin di terminal saraf presinaptik. ${ }^{21}$ Hal ini menyebabkan pengguna TCAs kronis mengalami penurunan tekanan darah selama induksi anestesi. Terapi TCAs jangka panjang dilaporkan menghabiskan katekolamin jantung, yang mempotensiasi depresi jantung dengan anestesi. ${ }^{22}$ Jika hipotensi intraoperatif terjadi dan vasopresor diperlukan, obat yang berefek langsung seperti norepinefrin direkomendasikan. Dopamin bekerja secara tidak langsung melalui pelepasan norepinefrin. TCAs dapat menghalangi pelepasan norepinefrin yang diinduksi dopamin, sehingga menumpulkan efek 
pressor tidak langsung yang dihasilkan oleh dopamin..$^{21}$ Karena blokade alfa-adrenergik oleh TCAs, aksi beta 2 dopamin menyebabkan lebih banyak vasodilatasi. ${ }^{23}$ Sebuah laporan kasus retrospektif menyarankan bahwa norepinefrin, tampak lebih menguntungkan daripada dopamin sebagai agen vasopresor lini pertama bagi mereka yang membutuhkan dukungan vasopresor untuk hipotensi yang diinduksi TCAs. Sebuah laporan serupa menggambarkan seorang pasien pada terapi TCAs kronis yang mengalami hipotensi dan resisten terhadap efedrin, fenilefrin, dan dopamin, tetapi diberi norepinefrin pada akhirnya berhasil. ${ }^{18}$ Pada pasien ini diagnosa dari sejawat SpKJ adalah skizofrenia sehingga hanya mendapatkan obat antipsikosis tanpa antidepresan.

Walaupun baru sedikit bukti kuat yang mengaitkan obat-obatan psikotropika dengan teratogenesis, cukup banyak yang enggan melanjutkan pengobatan selama kehamilan. Obat antipsikotik, baik konvensional maupun baru, dapat menyebabkan sejumlah efek pada neonatus, diantaranya hipotensi, gejala ekstrapiramidal, sedasi, takikardi, kegelisahan, distonia, gerakan mirip parkinson dan agranulositosis. Angka kejadian efek merugikan ini masih lebih rendah dibandingkan tingginya resiko yang harus dihadapi jika terjadi kekambuhan pada ibu bila obat dihentikan selama kehamilan dan persalinan. ${ }^{24}$ Tetap melanjutkan penggunaan obat selama kehamilan mungkin akan menjadi pilihan yang bijaksana pada pasien dengan riwayat ketidakstabilan emosi tanpa pengobatan. ${ }^{25} \mathrm{Hal}$ ini yang tampaknya berlaku pada pasien di mana selama kehamilan tetap mengkonsumsi obat antipsikotik. Sebuah penelitian eksperimental pada hewan coba menunjukkan bahwa clozapine diekskresikan dalam ASI, oleh karena itu ibu yang menerima pengobatan dengan clozapine tidak boleh menyusui. ${ }^{10}$ Sedangkan pemberian risperidone pada wanita hamil dan menyusui jika keuntungannya lebih besar dari resiko. ${ }^{11}$ Pada pasien ini sudah diinformasikan oleh sejawat SpKJ tidak diperkenankan memberikan ASI selama masih mengkonsumsi kedua obat tersebut. Pemberian antipsikotik pada kehamilan sesuai guidelines Miller ${ }^{26}$ (tabel 1).

\section{Tabel 1.PedomanAntipsikotikpada Kehamilan}

1 Dihentikan 4-10 minggu pascakonsepsi

2 Dihentikan 2 minggu sebelum kelahiran

3 Menggunakan obat yang kuat

4 Dihentikan jika muncul sindroma neuroleptik maligna

5 Segera dilanjutkan pasca persalinan

6 Hindari obat antiparkinson

Sumber : Miller LJ. Clinical strategies for the use of psychotropic drugs during pregnancy. Psychiatr Med. 1991;9:275-98

Analgesia neuraxial dianggap masih belum memberikan penanganan nyeri yang maksimal untuk seksio sesarea. Penggunaan analgesik multimodal pada pasien bertujuan untuk mendapatkan analgesia yang sinergis dengan minimal efek samping. ${ }^{27}$ Ketorolac tidak mengganggu ikatan opioid dan tidak mencetuskan depresi napas atau sedasi yang berkaitan dengan opioid meski digunakan bersamaan dengan opioid.

Ketorolac tidak dianjurkan untuk digunakan sebagai obat prabedah obstetrik atau untuk analgetik obstetrik karena belum diadakan penelitian yang adekuat mengenai hal ini dan karena diketahui mempunyai efek menghambat biosintesis prostaglandin atau kontraksi rahim dan sirkulasi fetus. Pernah dilaporkan adanya halusinasi bila Ketorolac diberikan pada pasien yang sedang menggunakan obat psikoaktif. Ketorolac tidak dianjurkan untuk pengobatan pada ibu menyusui, sekresi Ketorolac dalam air susu ibu terbatas. Rasio konsentrasi Ketorolac dalam air susu : plasma berkisar antara 0,015 dan 0,037 pada uji terhadap 10 wanita. ${ }^{28}$ Pada pasien ini pemberian Ketorolac sebaiknya dihindari.

\section{Simpulan}

Penatalaksanaan perioperatif yang baik pada pasien skizofrenia yang akan dilakukan tindakan operasi dan pembiusan diharapkan dapat mencegah terjadinya morbiditas dan mortalitas, sehingga diperlukan kerjasama multidisiplin antara anestesi, obstetri dan psikiater dalam penanganan pasien. 


\section{Daftar Pustaka}

1. Paschetta E, Berrisford G, Coccia F, Whitmore J, Wood AG, Pretlove S, et al. Perinatal psychiatric disorders: an overview. Am J Obstet Gynecol. 2014;210:501-U258.

2. Delgado JB, Frolich M. Psychiatric disorders. In: Suresh MS, Segal S, Preston RL, Fernando R, Mason CLT. Shnider and Levinson's anesthesia for obstetrics. 5th ed. Philadelphia: Lippincott Williams \& Wilkins; 2013, 647.

3. Parekh R. What is schizophrenia?[Internet]. American Psychiatric Association. 2017 [cited 19 September 2019]. Available from: https://www.psychiatry.org

4. Vigod SN, Ross LE. Epidemiology of psychotic symptoms during pregnancy and postpartum in women with schizophrenia. Current Women's Health Reviews, 2010,6,17-21.

5. Davies A, McIvor RJ, Kumar RC. Impact of childbirth on a series of schizophrenic mothers: a comment on the possible influence of oestrogen on schizophrenia. Schizophr Res 1995; 16:25-31.

6. Kendell RE, Wainwright S, Hailey A, Shannon B. The influence of childbirth on psychiatric morbidity. Psychol Med 1976; 6: 297-302.

7. Cok OY. Anesthesia for pregnant patient with psychiatric disorders. In: Gunaydin B, Ismail S, eds. Obstetric Anesthesia for Co-morbid Conditions. Switzerland: Springer; 2018, $145-54$.

8. O'Hara MW, Wisner KL. Perinatal mental illness: definition, description and aetiology. Best Pract Res Clin Obstet Gynaecol. 2014;28:3-12.

9. Bulbul F, Copoglu US, Alpak G, Unal A, Demir B, Tastan MF, et al. Electroconvulsive therapy in pregnant patients. Gen Hosp Psychiatry. 2013;35:636-9.

10. Anonim. Clozapine. Leaflet Nomor: DW-16RO. Ikapharmindo Putramas, Jakarta.

11. Anonim. Risperidone. Leaflet Nomor: 67503-02PS-05-PCPIUG. Dexa Medica, Palembang.

12. Reide PJW, Yentis SM. Anaesthesia for the obstetric patient with (non-obstetric) systemic disease. Best Pract Res Clin Obstet Gynaecol. 2010;24:313-26.

13. Sener EB, Kocamanoglu S, Ustun E, Tur A. Anesthetic management for cesarean delivery in a woman with Gilles de la Tourette's syndrome. Int J ObstetAnesth. 2006;15:163-5.

14. Vermersch C, Smadja S, Amselem O, Gay O, Marcellin L, Gaillard R, et al. Cesarean section and sismotherapy in a severe psychotic parturient: a case report. Ann Fr Anesth Reanim. 2013;32:711-4.

15. Wood M, Wood AJJ. Drugs and anesthesia. 2nd ed. Baltimore: Williams and Wilkins; 1990.

16. Ananth J, Parameswaran S, Gunatilake S, Burgoyne K, Sidhom T. Neuroleptic malignant syndrome and atypical antipsychotic drugs. J Clin Psychiatry. 2004;65:464-70.

17. Menteri Kesehatan Republik Indonesia. Pedoman Nasional Pelayanan Kedokteran Jiwa. Jakarta: Departemen Kesehatan. 2015.

18. Paul GB, Bruce FC, Robert KS, Michael KC, Christine S. Clinical Anesthesia. 6th ed. Philadelphia: Lippincott Williams and Wilkins;2009.

19. Hugh $\mathrm{CH}$, Talmage DE. Pharmacology and Physiology for Anesthesia: Foundations and Clinical Application. 1st ed. Philadelphia: Saunders Elsevier;2013. 
20. Sprung J, Schoenwald PK, Levy P, Krajewski LP. Treating intraoperative hypotension in a patient on long-term tricyclic antidepressants: A case of aborted aortic surgery. Anesthesiology 1997;86:990-2.

21. William CW, Christopher MG, David BH. Trauma: Emergency Resuscitation, Perioperative Anesthesia, Surgical Management. 1st ed. New York: Informa Healthcare USA;2007.

22. John FB, David CM, John DW. Morgan and Mikhail's Clinical Anesthesiology. 5th ed. New York: Appleton and Lange;2013.

23. Tran TP, Panacek EA, Rhee KJ, Foulke GE. Response to dopamine vs. norepinephrine in tricyclic antidepressant-induced hypotension. Acad Emerg Med 1997;4:864-8.

24. Potturi L, Viguera A. Psychotic disorders \& bipolar disorder. In: Pian-Smith MCM,
Leffert L, eds. Obstetric Anesthesia. New York: Cambridge; 2007, 597-603.

25. Kuller JA, Katz VL, Mc Mahon MJ, Wells SR, Bashford RA. Pharmacologic treatment of psychiatric disease in pregnancy and lactation: fetal and neonatal effects. Obstet Gynecol. 2006;87:789-94.

26. Miller LJ. Clinical strategies for the use of psychotropic drugs during pregnancy. Psychiatr Med. 1991;9:275-98.

27. Quach T, Singh S, Bellingham G. Analgesia post cesarean section. In: McConachie I, eds. Controversies in Obstetric Anesthesia and Analgesia. United Kingdom: Cambridge; 2012, 246-57.

28. Anonim. Ketorolac Trometamol Injeksi IV/ IM. Leaflet Nomor: BK0105 IMK. Hexpharm Jaya, Bekasi. 